\title{
Growth differentiation factor 15 levels in obese and healthy pregnancies and its relation to insulin resistance and insulin secretory function: a longitudinal study during and after pregnancy
}

\author{
Ulrika Andersson-Hall ${ }^{1}$, Louise Joelsson ${ }^{1}$, Pernilla Svedin ${ }^{1}$, Carina Mallard ${ }^{1}$, and Agneta \\ Holmäng ${ }^{1}$ \\ ${ }^{1}$ University of Gothenburg
}

August 14, 2020

\begin{abstract}
Objective/aim Growth-differentiation-factor 15 (GDF15) has been suggested to improve or protect beta-cell function. During pregnancy, beta-cell numbers and function increase to overcome the natural rise in insulin resistance during gestation. In this study, we longitudinally measured serum GDF15 levels during and after pregnancy in women of normal weight (NW) and in women with obesity (OB) and explored associations between GDF15 and changes in beta-cell function by homeostatic model assessment (HOMA). Methods The cohort participants were $38 \mathrm{NW}$ (BMI 22.3 \pm 1.7 ) and 35 OB (BMI 35.8 \pm 4.2 ). Blood was sampled and body composition measured at each trimester (T1, T2, and T3) and at 6, 12, and 18 months postpartum. Fasting glucose, insulin, and GDF15 were measured, and HOMA for insulin resistance (HOMA-IR) and beta cell function (HOMA-B) determined. Results GDF15 levels increased significantly each trimester and were 200 -fold higher at T3 than in the nonpregnant postpartum state. GDF15 was higher in NW than OB in T3, but was lower in NW at 18 months after pregnancy. GDF15 correlated inversely with BMI and fat-free mass at T3. Low GDF15 in T1 was associated with lower incidence of nausea and with carrying a male fetus. GDF15 at T2 and T3 and the increases between trimesters associated with increased HOMA-B over the course of pregnancy. Increases in GDF15 either early or late in pregnancy were associated with a reduction in blood glucose between T2 and T3. Conclusion Large gestational upregulation of GDF15 levels may help increase insulin secretory function to overcome pregnancy-induced insulin resistance.
\end{abstract}

\section{Abbreviations}

GDF15 Growth differentiation factor 15

HOMA-B Homeostatic model assessment for beta cell function

HOMA-IR Homeostatic model assessment for insulin resistance

NW Women of normal weight

OB Women with obesity

\section{Introduction}

Pregnancy is a natural state of insulin resistance, which progressively increases to ensure adequate glucose transport to the growing fetus ${ }^{1,2}$. In women with normal glucose tolerance, beta cells proliferate and their function is enhanced to increase insulin secretion and thereby compensate for the increased insulin resistance $^{3,4}$. When insulin resistance becomes too great or beta cell function does not respond adequately, glucose tolerance is impaired, leading to gestational diabetes, which has important implications for pregnancy outcome and the long-term health of mother and $\operatorname{child}^{5,6}$. 
Obesity is a major driver of insulin resistance, and both pre-gestational obesity and large increases in maternal fat mass during pregnancy are risk factors for gestational diabetes. The mechanisms of insulin resistance during pregnancy are complex and are believed to be caused partly by hormones from the placenta and partly by other obesity- and pregnancy-related factors that are not fully understood ${ }^{7-9}$.

Growth differentiation factor 15 (GDF15), a member of the transforming growth factor-beta family, is a cytokine that was first discovered to be involved in inflammation and stress pathways; it was later found to be an appetite suppressant and a potential weight loss therapeutic ${ }^{10-12}$. GDF15 has also been linked to glucose metabolism, although the mechanism is not clear. Circulating GDF15 has been positively related to beta cell function in patients with severe obesity ${ }^{13}$ and also rescues compromised beta cells in human islets ${ }^{14}$. In cross-sectional studies, increased levels of GDF15 have been noted in subjects with obesity and diabetes ${ }^{15-17}$.

Maternal GDF15 levels have been reported to increase across gestation, probably due to placental expression ${ }^{18,19}$, and high levels of GDF15 have been linked to pregnancy-related nausea and hyperemesis $^{20,21}$. However, it is not known how GDF-15 levels increase during pregnancy in normoglycemic women that differ in body mass index (BMI) and whether these levels are linked to changes in insulin resistance and insulin secretory function.

In this study, we measured GDF15 levels during and after pregnancy in women of normal weight (NW) and those with obesity (OB) and sought to determine whether increasing levels of GDF15 are associated with improvements in beta cell function and glucose metabolism. We hypothesized that a rise in GDF15 levels during pregnancy might be differentially regulated according to maternal BMI and that GDF15 is linked to the increasing beta cell function needed to maintain normal glucose levels during pregnancy-induced insulin resistance.

\section{Methods}

\section{Ethical approval}

The study was approved by the Regional Ethical Review Board in Gothenburg (Dnr 402-08). All women received oral and written information about the study and gave informed written consent before enrolment.

\section{Subjects}

Pregnant NW (BMI 18.5-24.9 $\mathrm{kg} / \mathrm{m}^{2}$ ) and OB (BMI [?]30 kg/m²), aged 20-45 years, were recruited from six antenatal health units in the Gothenburg area as part of the Pregnancy Obesity Nutrition and Child Health $(\mathrm{PONCH})$ study, as described ${ }^{22}$. Exclusion criteria were non-European descent, diabetes mellitus (type 1, type 2, or gestational) or other chronic diseases, pregnancy-related complications, use of tobacco or neuroleptic drugs, and vegetarianism or veganism. The women came to the Sahlgrenska University Hospital for study visits once each trimester (weeks 8-12, 24-26, and 35-37; T1, T2, and T3, respectively) during pregnancy and at 6,12 , and 18 months ( \pm 10 days) after pregnancy. Gestational age at study visits were on average $81 \pm 8$ days at T1, $175 \pm 8$ days at T2 and $253 \pm 7$ days at T3, and did not differ between NW and OB $(p>0.4)$.

GDF15 was measured in a subset of the total $132 \mathrm{NW}$ and $50 \mathrm{OB}$ that enlisted in PONCH. Subjects for the present study were selected from those who had complete serum samples and body composition measurements from T1 or T2 until 18 months after pregnancy. Of $71 \mathrm{NW}$ who had complete visits, 38 were randomly selected. Selected NW did not differ from non-selected NW in BMI, body composition, or homeostatic model assessment of insulin resistance (HOMA-IR). All OB who had the maximal number of visits were selected. The number of subjects for NW after pregnancy was matched with $\mathrm{OB}$ ( $\mathrm{n}=30$ after pregnancy). A few subjects were lacking in T2 samples. This resulted in differences in the numbers for visits at T1 (38 NW and $28 \mathrm{OB}), \mathrm{T} 2(30 \mathrm{NW}$ and $29 \mathrm{OB})$, and T3 (38 NW and $35 \mathrm{OB})$ and at 6 months (30 NW and $30 \mathrm{OB}$ ), 12 months (30 NW and $24 \mathrm{OB}$ ), and 18 months (30 NW and $11 \mathrm{OB}$ ) postpartum. The reasons given for postpartum drop-outs in the OB group were lack of time, moving to a different part of Sweden, or a new pregnancy. 


\section{Study visits}

All visits during and after pregnancy took place in the morning after an overnight fast and included collection of anthropometric and body composition measurements, blood samples and completion of life-style questionnaires, as described elsewhere in detail ${ }^{22}$. As part of the PONCH study, the pregnant women were randomized into dietary intervention or control subgroups ${ }^{23}$; the intervention subgroup received dietary counseling to increase adherence with Nordic Nutrition Recommendations. In the current study, none of the outcome measures differed between women in the dietary intervention and those in control subgroups, and subjects in the dietary subgroups were evenly distributed in the NW and OB groups. Therefore, data for the intervention/control subgroups were combined in all analyses.

Body composition was measured by ADP with the Bod Pod Gold Standard system (Bod Pod 2007 A, Life Measurement, Concord, CA) and software versions 4.2.1 and 5.2.0. Adjustments were made for increased hydration of fat-free mass (FFM) during pregnancy in measurements made in T2 and T3 as described ${ }^{24}$. The coefficient of variation (CV) for body composition measurements on our equipment was $2.4 \%$. As part of the life-style questionnaires, the women were asked whether they had experienced nausea during pregnancy. This question was missing for part of the study resulting in a total of 54 women from the present study answering the question.

\section{Biochemical analysis}

Blood glucose and insulin were analysed with a Cobas Modular system (Roche Diagnostics, Risch, Switzerland) at the Clinical Chemistry Laboratory, Sahlgrenska University Hospital (accredited in accordance with the International Standard ISO 15189:2007). HOMA-IR was calculated as (fasting glucose $\times$ fasting insulin) $/ 22.5$ and HOMA-B as $(20 \times \text { fasting insulin)/(fasting glucose }-3.5)^{25}$. GDF15 was analysed with an ELISA (Human GDF-15 Quantikine Elisa Kit, R\&D Systems, Minneapolis, MN, USA); serum samples during and after pregnancy were diluted 1:64 and 1:4, respectively. The intra- and inter-assay CVs for GDF15 measurements were $1.7 \%$ and $7 \%$, respectively.

\section{Statistical analysis}

The number of subjects selected for the study was based on power calculations of GDF15 differences between NW or OB in previous studies in nonpregnant subjects ${ }^{16,17}$; a minimum of 8 subjects was needed for a power of 0.95 and alpha $=0.05$. Differences in ordered categorical variables between the NW and OB groups were assessed with chi-square or Fisher's exact test; between-group differences for continuous variables were assessed with a $t$ test, and within-group comparisons for continuous variables were assessed with a paired $t$ test. Associations between GDF15 and changes in glucose, insulin, HOMA-IR, or HOMA-B were analysed with Pearson correlation within groups or linear regression models, adjusted for gestational age and maternal BMI and age at T1, for the whole population. The diagnostic plots for residuals were reviewed and met assumptions of normality and homoscedasticity. Categorical variables were expressed as number or percentage, and continuous variables as mean $+-\mathrm{SD}$. All tests were two-tailed; $p<0.05$ was considered statistically significant.

\section{Results}

\section{Subject characteristics and glucose metabolism}

Age, parity, education, fetal gender, and birth weight did not differ between the NW and OB groups (Table 1). BMI, fat mass (FM), and fat free mass (FFM) were lower in NW than OB during and after pregnancy; at 18 months after pregnancy, the difference in FFM had disappeared. During pregnancy, total body weight $(p=0.016)$ and FM $(p=0.001)$ increased more in NW, but the gain in FFM was similar in the two groups. There was no difference between NW and OB in self-reported nausea during pregnancy. There was, however, a significant difference in nausea between women carrying a female or male fetus (nausea reported in $72 \%$ of women carrying a female fetus and $42 \%$ in women carrying male a fetus, $p=0.03$ ).

Fasting blood glucose, HOMA-IR, and HOMA-B were lower in NW at all time points during and after 
pregnancy (Table 1). In NW during pregnancy, blood glucose levels decreased whereas HOMA-IR and HOMA-B increased ( $p=0.04, p=0.014$, and $p<0.001$ for changes between T1 and T3 in glucose, HOMAIR and HOMA-B respectively). In OB, HOMA-IR and HOMA-B increased significantly during pregnancy, but the change in blood glucose was not significant $(p=0.20, p<0.001$, and $p<0.001$ for changes between T1 and T3 in glucose, HOMA-IR and HOMA-B respectively). After pregnancy in both groups, glucose levels increased whereas HOMA-IR and HOMA-B decreased $(p<0.001$ for all changes between T3 and 6months in glucose, HOMA-IR and HOMA-B in both NW and OB).

\section{GDF15 levels during and after pregnancy}

In NW, serum GDF15 increased 40-fold in T1 to 200-fold in T3 compared with nonpregnant values (i.e. after pregnancy), as shown in Fig 1A. OB showed a similar trend although the increases were slightly lower in T2 and T3 than in NW. After the initial postpartum decrease, GDF15 did not significantly change between 6, 12 , and 18 months in either group. GDF15 was generally higher in OB than in NW after pregnancy, but the difference was significant only at 18 months.

In line with the differences in GDF15 levels between the two groups during pregnancy, GDF15 levels correlated negatively with body weight and BMI at $\mathrm{T} 2(\mathrm{R}=-0.385, p=0.003$ and $\mathrm{R}=-0.336, p=0.009$, respectively) and $\mathrm{T} 3(\mathrm{R}=-0.344, p=0.003$ and $\mathrm{R}=-0.289, p=0.013$, respectively). In analyses of body composition, GDF15 correlated negatively with FFM (but not FM) in NW at both $\mathrm{T} 1(\mathrm{R}=-0.433, p=$ $0.007)$ and $\mathrm{T} 3(\mathrm{R}=-0.336, p=0.042)$. However, after adjustment for maternal BMI, only the negative correlation between GDF15 and FFM at T3 remained significant (Fig. 1B). When analyzing the BMI groups separately, GDF15 correlated negatively with FFM (but not FM) in NW at both T1 and T3 (R=-0.433, $\mathrm{P}=0.007$ at $\mathrm{T} 1$ and $\mathrm{R}=-0.336, P=0.042$ at $\mathrm{T} 3$ ). In the $\mathrm{OB}$ group, GDF15 during pregnancy did not correlate significantly with weight, BMI, or body composition, although the correlation between GDF15 and FFM at T2 narrowly missed significance $(p=0.051)$. After pregnancy, GDF15 correlated positively with FM at 18 months, but not after adjustment for BMI (Fig. 1C).

GDF15 levels were not consistently associated with changes in weight or body composition, apart from a negative association between early GDF15 change (T1 to T2) and gestational FM gain (T1 to T3) in NW $(\mathrm{R}=-0.382, p=0.037)$.

In analysis by fetal sex, GDF15 at T1 was significantly higher in women carrying a female fetus than in those carrying a male fetus (Fig. $1 \mathrm{D}$ ). The difference remained significant after adjustment for maternal BMI. When analyzing the relationship between GDF15 and nausea, there was a trend for lower GDF15 at T1 in women not reporting nausea compared to those that did $(12046+-4298 \mathrm{ng} / \mathrm{L}$ vs $13893+-5081 \mathrm{ng} / \mathrm{L}$, respectively, $p=0.12$ ). Dividing GDF15 at T1 into quarters, the women with the lowest quarter of GDF15 reported lower incidence of nausea compared to the rest ( $33 \%$ vs $64 \%$, respectively, $\mathrm{p}=0.04)$. This difference remained significant after BMI adjustment $(p=0.04)$, but was non-significant after adjustment for fetal sex $(p=0.16)$.

\section{Associations between GDF15 expression and beta cell function during and after pregnancy}

Associations between GDF15 and pregnancy induced increases in insulin resistance and beta cell function from T1-T3 are shown in Table 2. In this model (adjusted for BMI, age and gestational age), absolute levels of GDF15 at T2 and T3 and increases in GDF15 between trimesters associated with the increase in HOMA-B (Table 2). For unadjusted correlations within groups, there were also significant associations between increases in HOMA-B and GDF15, although the timing differed slightly between groups. In NW, HOMA-B increase associated with GDF15 at T2 $(\mathrm{R}=0.467, p=0.016)$ and with GDF15 change T2 to T3 $(\mathrm{R}=0.394, p=0.046)$. In OB, HOMA-B increase associated with GDF15 change T1 to T2 $(\mathrm{R}=0.664, p<$ $0.001)$ and with change in GDF15 T1 toT3 $(\mathrm{R}=0.388, p=0.046)$.

Fasting blood glucose decreased significantly late in pregnancy $(p=0.008)$. This decrease between T2 and T3 was inversely associated with changes in GDF15 from T1 to T2 and from T2 to T3 (Fig. 2).

Since GDF15 levels did not change significantly between time points after pregnancy (Fig. 1A), associations 
between measures of glucose metabolism and changes in GDF15 after pregnancy were not deemed relevant. Only associations for absolute values at 6,12 , and 18 months were investigated. GDF15 did not correlate with HOMA-IR or HOMA-B at 6 or 12 months. At 18 months, however, GDF15 was significantly associated with HOMA-B (beta $=0.301, p=0.039)$ and HOMA-IR (beta $=0.304, p=0.009)$ among all women after adjustment for maternal age and BMI. In subgroup analyses, GDF15 associated significantly with HOMA-B in NW (beta $=0.424, p=0.031)$ and with HOMA-IR in OB (beta $=0.587, p=0.048)$.

\section{Discussion}

This is the first study to both longitudinally measure GDF15 during and after pregnancy and to compare these levels in NW and OB women. For the first time in normoglycemic women, we also linked GDF15 levels during pregnancy with beta cell function and glucose levels. Circulating GDF15 increased throughout pregnancy, and GDF15 levels in late pregnancy were up to 200-fold higher than in the nonpregnant state. The increases were higher in NW than OB, and the levels correlated inversely with FFM. Further, the increasing GDF15 levels were associated with increased beta cell function and lower glucose levels during the later part of pregnancy.

Diabetes and obesity are considered to be conditions of inflammation and metabolic stress and are associated with high GDF15 levels ${ }^{15-17}$. However, the link between GDF15 and glucose metabolism is not clear from previous studies. Pregnancy is a naturally occurring state of increasing insulin resistance and insulin secretory capacity, which peak in late pregnancy ${ }^{9}$ and is therefore a good model for studying longitudinal factors that might affect beta cell function. We found that in normoglycemic women, increasing GDF15 levels during pregnancy were associated with increased HOMA-B and decreased fasting glucose levels in late pregnancy, without effecting insulin resistance. Previous cross-sectional studies have shown higher serum levels of GDF15 in patients with insulin resistance or type 2 diabetes $^{16,17,26}$, and a study investigating GDF15 in chinese pregnant women linked high GDF15 to gestational diabetes ${ }^{27}$. Other studies show that GDF15 positively affects beta cells, as judged from its ability to rescue beta cell function in compromised human islets and to reduce the incidence of diabetes in nonobese diabetic mice ${ }^{14}$. In addition, GDF15 was positively associated with beta cell function in a cross-sectional study of obese subjects ${ }^{13}$. Intriguingly, in a longitudinal study, GDF15 levels predicted impairment of glucose metabolism in obese subjects ${ }^{28}$, suggesting that the increased concentrations of GDF15 seen in obesity were insufficient to improve beta cell function.

We found that postpartum GDF15 levels were higher in OB than in NW (400vs $350 \mathrm{ng} / \mathrm{l}$ ). These levels are comparable to those in healthy nonpregnant subjects in previous studies ${ }^{13,16,17,29,30}$. In contrast, during pregnancy, the increases in GDF15 were greater in NW, and reached higher levels at T2 and T3, than in OB. In agreement with a previous study (that did not include OB), GDF15 during pregnancy correlated inversely with BMI at the start of pregnancy ${ }^{20}$. The large increases in circulating GDF15 during pregnancy are believed to be of placental origin ${ }^{18}$, and differences in the placentas of NW and OB might be of importance for the release of GDF15. For example, macrophage M1 infiltration in the decidua parietalis during pregnancy is lower in OB than $\mathrm{NW}^{31}$. This difference was speculated to indicate a compensation mechanism for the proinflammatory state in OB to ensure healthy pregnancy outcomes. Presumably, placentas from women who differ in BMI also differ in expression of immune factors such as GDF-15 and other cytokines; such differences could influence immune reactions and metabolism during pregnancy. However, a conclusive explanation for the difference in GDF15 levels between NW and OB in our study is lacking and needs to be clarified in future research.

We found an inverse correlation between GDF15 increase during pregnancy and FM gain in NW but did not see a relationship between GDF15 and gestational weight gain. Increases in GDF15 mediate adiposity resistance $^{32}$ and are linked to reductions in body weight ${ }^{12,33,34}$ and in FM ${ }^{35}$. The effect of GDF15 on weight loss is thought to be associated with appetite reduction regulated by binding to the GDNF family receptor $\alpha$-like (GFRAL) receptor in the hindbrain ${ }^{32,36}$. The effect of GDF15 on pregnancy-related weight gain has not previously been reported, but GDF15 has been linked to pregnancy-related nausea and hyperemesis gravidarum ${ }^{20,21}$. We confirmed these earlier findings by showing that women with the lowest quartile of GDF15 in T1 reported lower incidence of pregnancy-related nausea. Interestingly, hyperemesis may be more 
common in women of low $\mathrm{BMI}^{37}$ and in those carrying a female fetus ${ }^{38,39}$. We did not see a difference in nausea between NW and OB, but we did see a higher incidence of nausea in women carrying female fetuses. We also found that high GDF15 levels were linked to carrying a female fetus. I.e. GDF15 could potentially be the link between nausea and fetal sex; in support of this we found that the difference in nausea between GDF15 quarters was abolished when adjusted for fetal sex. GDF15 inhibition has been suggested as a treatment for hyperemesis gravidarum ${ }^{20,21}$. However, if the link between GDF15 and beta cell function we found proves to be casual, manipulating GDF15 action might disturb glucose homeostasis.

After a large postpartum reduction in circulating GDF15, there were no changes between 6 and 18 months after pregnancy; glucose metabolism followed a similar pattern. At 18 months after pregnancy GDF15 was positively associated with HOMA-B for all women and NW and, in OB, with HOMA-IR. The latter finding is in agreement with cross-sectional studies linking insulin resistance and GDF15 in nonpregnant OB ${ }^{17,} 28$. This association can be explained by the higher release of GDF15 in inflammatory conditions such as insulin resistance and obesity as discussed above.

The major strength of the current study is the longitudinal design comprising three time points during pregnancy and three time points after pregnancy, all involving identical study visits at a single center. Our subjects were well characterized through blood sampling and use of a reference method to measure body composition. However, oral glucose tolerance testing in addition to HOMA calculations would have provided a more extensive evaluation of glucose metabolism and insulin release. As in all such studies, additional limitations include the difficulty of proving causation in relationships, recruitment bias, and generalizability. With a focus on health and anthropometric measurements, recruited women are generally more inclined to keep healthy habits. However, relationships among the various factors measured should not be affected by this potential bias. A final limitation was the reduced statistical power resulting from the number of drop-outs in the OB group for the last visit at 18 months after pregnancy.

In conclusion, we found that the serum level of GDF15 increases throughout pregnancy, and does so to greater extent in NW than $\mathrm{OB}$, and is associated with increased insulin secretory function in normoglycemic pregnancies. Adding to previous research in nonpregnant subjects, our findings suggest that GDF15 has a beneficial effect on beta cell function and may have implications for treatment to overcome insulin resistance . More mechanistic studies will be needed to confirm the effect of GDF15 on beta cells during pregnancy.

Acknowledgements We thank all the women who participated in the study, and registered dietician Evelina Järvinen for expert caretaking and measurements during study visits.

Ethical approval The study was approved by the Regional Ethical Review Board in Gothenburg (Dnr 40208). All women received oral and written information about the study and gave informed written consent before enrolment.

Author contributions Conception, data acquisition, or data analysis and interpretation; UAH, PS, AH. Drafting or revising article for intellectual content; UAH, LJ, CM, AH. Final appoval of article; UAH, LJ, PS, CM, AH

\section{References}

1. Barbour LA, McCurdy CE, Hernandez TL, Kirwan JP, Catalano PM, Friedman JE. Cellular mechanisms for insulin resistance in normal pregnancy and gestational diabetes. Diabetes Care . 2007;30 Suppl 2:S112-9.

2. Catalano PM. Obesity, insulin resistance, and pregnancy outcome. Reproduction . 2010;140(3):365-71.

3. Baeyens L, Hindi S, Sorenson RL, German MS. $\beta$-Cell adaptation in pregnancy. Diabetes, Obesity and Metabolism . 2016;18:63-70.

4. Xue Y, Liu C, Xu Y, Yuan Q, Xu K, Mao X, et al. Study on pancreatic islet adaptation and gene expression during pregnancy in rats. Endocrine . 2010;37(1):83-97. 
5. Homko C, Sivan E, Chen X, Reece EA, Boden G. Insulin secretion during and after pregnancy in patients with gestational diabetes mellitus. J Clin Endocrinol Metab . 2001;86(2):568-73.

6. Buchanan TA, Xiang A, Kjos SL, Watanabe R. What is gestational diabetes? Diabetes care . 2007;30(Supplement 2):S105-S11.

7. Catalano PM. Trying to understand gestational diabetes. Diabet Med . 2014;31(3):273-81.

8. Wang Y, Luo B-R. The association of body composition with the risk of gestational diabetes mellitus in Chinese pregnant women: A case-control study. Medicine . 2019;98(42).

9. Kampmann U, Knorr S, Fuglsang J, Ovesen P. Determinants of Maternal Insulin Resistance during Pregnancy: An Updated Overview. Journal of Diabetes Research . 2019;2019.

10. Hsu JY, Crawley S, Chen M, Ayupova DA, Lindhout DA, Higbee J, et al. Non-homeostatic body weight regulation through a brainstem-restricted receptor for GDF15. Nature . 2017;550(7675):255-9.

11. Mullican SE, Lin-Schmidt X, Chin CN, Chavez JA, Furman JL, Armstrong AA, et al. GFRAL is the receptor for GDF15 and the ligand promotes weight loss in mice and nonhuman primates.Nat Med . 2017;23(10):1150-7.

12. Mullican SE, Rangwala SM. Uniting GDF15 and GFRAL: Therapeutic Opportunities in Obesity and Beyond.Trends Endocrinol Metab . 2018;29(8):560-70.

13. Schernthaner-Reiter MH, Itariu BK, Krebs M, Promintzer-Schifferl M, Stulnig TM, Tura A, et al. GDF15 reflects beta cell function in obese patients independently of the grade of impairment of glucose metabolism. Nutr Metab Cardiovasc Dis . 2019;29(4):334-42.

14. Nakayasu ES, Syed F, Tersey SA, Gritsenko MA, Mitchell HD, Chan CY, et al. Comprehensive Proteomics Analysis of Stressed Human Islets Identifies GDF15 as a Target for Type 1 Diabetes Intervention. Cell Metab . 2020;31(2):363-74 e6.

15. Bao X, Borne Y, Muhammad IF, Nilsson J, Lind L, Melander O, et al. Growth differentiation factor 15 is positively associated with incidence of diabetes mellitus: the Malmo Diet and Cancer-Cardiovascular Cohort. Diabetologia . 2019;62(1):78-86.

16. Dostalova I, Roubicek T, Bartlova M, Mraz M, Lacinova Z, Haluzikova D, et al. Increased serum concentrations of macrophage inhibitory cytokine- 1 in patients with obesity and type 2 diabetes mellitus: the influence of very low calorie diet. Eur J Endocrinol . 2009;161(3):397-404.

17. Vila G, Riedl M, Anderwald C, Resl M, Handisurya A, Clodi M, et al. The relationship between insulin resistance and the cardiovascular biomarker growth differentiation factor-15 in obese patients. Clin Chem . 2011;57(2):309-16.

18. Moore AG, Brown DA, Fairlie WD, Bauskin AR, Brown PK, Munier ML, et al. The transforming growth factor-ss superfamily cytokine macrophage inhibitory cytokine-1 is present in high concentrations in the serum of pregnant women. J Clin Endocrinol Metab . 2000;85(12):4781-8.

19. Michelsen TM, Henriksen T, Reinhold D, Powell TL, Jansson T. The human placental proteome secreted into the maternal and fetal circulations in normal pregnancy based on 4 -vessel sampling. FASEB $J$. 2019;33(2):2944-56.

20. Petry CJ, Ong KK, Burling KA, Barker P, Goodburn SF, Perry JR, et al. Associations of vomiting and antiemetic use in pregnancy with levels of circulating GDF15 early in the second trimester: A nested case-control study. Wellcome open research . 2018;3.

21. Fejzo MS, Sazonova OV, Sathirapongsasuti JF, Hallgrímsdóttir IB, Vacic V, MacGibbon KW, et al. Placenta and appetite genes GDF15 and IGFBP7 are associated with hyperemesis gravidarum. Nature communications . 2018;9(1):1-9. 
22. Andersson-Hall U, Svedin P, Svensson H, Lonn M, Mallard C, Holmang A. Longitudinal changes in adipokines and free leptin index during and after pregnancy in women with obesity. Int $J$ Obes (Lond) . $2020 ; 44(3): 675-83$.

23. Bosaeus M, Hussain A, Karlsson T, Andersson L, Hulthen L, Svelander C, et al. A randomized longitudinal dietary intervention study during pregnancy: effects on fish intake, phospholipids, and body composition. Nutr J . 2015;14:1.

24. Bosaeus M, Andersson-Hall U, Andersson L, Karlsson T, Ellegard L, Holmang A. Body Composition During Pregnancy: Longitudinal Changes and Method Comparisons. Reprod Sci . 2020.

25. Matthews D, Hosker J, Rudenski A, Naylor B, Treacher D, Turner R. Homeostasis model assessment: insulin resistance and $\beta$-cell function from fasting plasma glucose and insulin concentrations in man. Diabetologia . 1985;28(7):412-9.

26. Schindler K, Vila G, Hoppichler F, Lechleitner M, Luger A, Anderwald C, et al. The impact of type 2 diabetes on circulating adipokines in patients with metabolic syndrome.Obes Facts . 2012;5(2):270-6.

27. Tang M, Luo M, Lu W, Wang S, Zhang R, Liang W, et al. Serum growth differentiation factor 15 is associated with glucose metabolism in the third trimester in Chinese pregnant women. Diabetes Res Clin $\operatorname{Pr}$. 2019;156:107823.

28. Kempf T, Guba-Quint A, Torgerson J, Magnone MC, Haefliger C, Bobadilla M, et al. Growth differentiation factor 15 predicts future insulin resistance and impaired glucose control in obese nondiabetic individuals: results from the XENDOS trial.Eur J Endocrinol . 2012;167(5):671-8.

29. Patel N, Pasupathy D, Poston L. Determining the consequences of maternal obesity for offspring health. Experimental physiology . 2015;100(12):1421-8.

30. Dolo PR, Yao L, Liu PP, Widjaja J, Meng S, Li C, et al. Effect of sleeve gastrectomy on plasma growth differentiation factor-15 (GDF15) in human. The American Journal of Surgery . 2020.

31. Laskewitz A, van Benthem K, Kieffer T, Faas M, Verkaik-Schakel R, Plösch T, et al. The influence of maternal obesity on macrophage subsets in the human decidua. Cellular immunology . 2019;336:75-82.

32. Tsai VW-W, Zhang HP, Manandhar R, Schofield P, Christ D, Lee-Ng KKM, et al. GDF15 mediates adiposity resistance through actions on GFRAL neurons in the hindbrain AP/NTS. International Journal of Obesity . 2019:1-11.

33. Day EA, Ford RJ, Smith BK, Mohammadi-Shemirani P, Morrow MR, Gutgesell RM, et al. Metformininduced increases in GDF15 are important for suppressing appetite and promoting weight loss. Nature Metabolism . 2019;1(12):1202-8.

34. Coll AP, Chen M, Taskar P, Rimmington D, Patel S, Tadross JA, et al. GDF15 mediates the effects of metformin on body weight and energy balance. Nature . 2020;578(7795):444-8.

35. Zhang H, Fealy CE, Kirwan JP. Exercise training promotes a GDF15-associated reduction in fat mass in older adults with obesity. American Journal of Physiology-Endocrinology and Metabolism . 2019;316(5):E829E36.

36. Yang L, Chang C-C, Sun Z, Madsen D, Zhu H, Padkjær SB, et al. GFRAL is the receptor for GDF15 and is required for the anti-obesity effects of the ligand. Nature medicine . 2017;23(10):1158.

37. Cedergren M, Brynhildsen J, Josefsson A, Sydsjö A, Sydsjö G. Hyperemesis gravidarum that requires hospitalization and the use of antiemetic drugs in relation to maternal body composition. American journal of obstetrics and gynecology . 2008;198(4):412. e1-. e5.

38. Rashid M, Rashid M, Malik F, Herath R. Hyperemesis gravidarum and fetal gender: a retrospective study. Journal of Obstetrics and Gynaecology . 2012;32(5):475-8. 
39. Fiaschi L, Nelson-Piercy C, Tata LJ. Hospital admission for hyperemesis gravidarum: a nationwide study of occurrence, reoccurrence and risk factors among 8.2 million pregnancies.Human Reproduction . 2016;31(8):1675-84.

Table 1 Maternal characteristics

\begin{tabular}{|c|c|c|c|}
\hline & $\mathrm{NW}(n=38)$ & $\mathrm{OB}(n=35)$ & $p(\mathrm{NW}$ vs $\mathrm{OB})$ \\
\hline Age $(y)$ & $31.3 \pm 3.4^{\mathrm{a}}$ & $31.4 \pm 4.0$ & 0.92 \\
\hline Nulliparous (\%) & $45 \%$ & $51 \%$ & 0.64 \\
\hline Male/female fetus (n) & $20 / 18$ & $20 / 15$ & 0.44 \\
\hline $\begin{array}{l}\text { Birth weight of child } \\
(\mathrm{kg})\end{array}$ & $3.78 \pm 0.39$ & $3.86 \pm 0.50$ & 0.46 \\
\hline $\begin{array}{l}\text { Nausea during } \\
\text { pregnancy }(\%)\end{array}$ & $53 \%$ & $58 \%$ & 0.79 \\
\hline \multicolumn{4}{|l|}{ Pregnancy } \\
\hline $\operatorname{BMI}\left(\mathrm{kg} / \mathrm{m}^{2}\right), \mathrm{T} 1$ & $22.3 \pm 1.7$ & $35.8 \pm 4.2$ & $<0.001$ \\
\hline Fat mass $(\mathrm{kg}), \mathrm{T} 1$ & $16.7 \pm 4.5$ & $47.2 \pm 11.1$ & $<0.001$ \\
\hline Fat free mass $(\mathrm{kg}), \mathrm{T} 1$ & $45.1 \pm 4.4$ & $54.0 \pm 6.3$ & $<0.001$ \\
\hline Glucose (mmol/l), T1 & $4.69 \pm 0.39$ & $4.88 \pm 0.41$ & 0.065 \\
\hline HOMA-IR, T1 & $1.15 \pm 0.99$ & $2.82 \pm 1.33$ & $<0.001$ \\
\hline HOMA-B $(\%)$, T1 & $92 \pm 40$ & $197 \pm 99$ & $<0.001$ \\
\hline $\begin{array}{l}\text { Fat mass gain }(\mathrm{kg}), \mathrm{T} 1 \text { to } \\
\mathrm{T} 3\end{array}$ & $4.0 \pm 2.9$ & $1.1 \pm 4.0$ & 0.001 \\
\hline $\begin{array}{l}\text { Fat-free mass gain }(\mathrm{kg}) \text {, } \\
\text { T1 to T3 }\end{array}$ & $6.7 \pm 1.8$ & $6.5 \pm 2.8$ & 0.68 \\
\hline $\begin{array}{l}\text { Glucose change, } \\
(\mathrm{mmol} / \mathrm{l}), \mathrm{T} 1 \text { to } \mathrm{T} 3\end{array}$ & $-0.23 \pm 0.43$ & $-0.09 \pm 0.37$ & 0.19 \\
\hline $\begin{array}{l}\text { HOMA-IR change, } \mathrm{T} 1 \text { to } \\
\mathrm{T} 3\end{array}$ & $0.43 \pm 0.97$ & $1.98 \pm 1.52$ & $<0.001$ \\
\hline $\begin{array}{l}\text { HOMA-B change, }(\%), \\
\text { T1 to T3 }\end{array}$ & $93 \pm 77$ & $189 \pm 203$ & 0.01 \\
\hline After pregnancy & & & \\
\hline BMI $\left(\mathrm{kg} / \mathrm{m}^{2}\right), 6$ months & $22.1 \pm 1.9$ & $34.8 \pm 4.8$ & $<0.001$ \\
\hline BMI $\left(\mathrm{kg} / \mathrm{m}^{2}\right), 18$ months & $22.0 \pm 1.9$ & $33.1 \pm 5.0$ & $<0.001$ \\
\hline Fat mass $(\mathrm{kg}), 6$ months & $16.9 \pm 5.0$ & $46.9 \pm 12.7$ & $<0.001$ \\
\hline Fat mass $(\mathrm{kg}), 18$ months & $15.5 \pm 5.4$ & $43.2 \pm 13.1$ & $<0.001$ \\
\hline $\begin{array}{l}\text { Fat-free mass }(\mathrm{kg}), 6 \\
\text { months }\end{array}$ & $44.8 \pm 3.7$ & $52.4 \pm 6.3$ & $<0.001$ \\
\hline $\begin{array}{l}\text { Fat-free mass }(\mathrm{kg}), 18 \\
\text { months }\end{array}$ & $45.5 \pm 4.5$ & $48.4 \pm 4.4$ & 0.076 \\
\hline $\begin{array}{l}\text { Glucose }(\mathrm{mmol} / \mathrm{l}), 6 \\
\text { months }\end{array}$ & $4.95 \pm 0.29$ & $5.22 \pm 0.45$ & 0.007 \\
\hline $\begin{array}{l}\text { Glucose }(\mathrm{mmol} / \mathrm{l}), 18 \\
\text { months }\end{array}$ & $4.97 \pm 0.30$ & $5.19 \pm 0.41$ & 0.061 \\
\hline HOMA-IR, 6 months & $0.96 \pm 0.36$ & $2.86 \pm 1.73$ & $<0.001$ \\
\hline HOMA-IR, 18 months & $1.35 \pm 0.56$ & $2.79 \pm 1.38$ & $<0.001$ \\
\hline HOMA-B (\%), 6 months & $60 \pm 22$ & $147 \pm 71$ & $<0.001$ \\
\hline HOMA-B (\%), 18 months & $86 \pm 44$ & $141 \pm 50$ & 0.001 \\
\hline
\end{tabular}

${ }^{a}$ Values are mean \pm SD (except for parity, fetal sex and nausea) HOMA-IR, homeostatic model assessment for insulin resistance; HOMA-B; homeostatic model assessment for beta cell function; NW, women of normal 
weight; $\mathrm{OB}$, women with obesity; T1, trimester 1;T3, trimester 3

Table 2 Regression analysis of associations between GDF15 and changes in glucose and insulin metabolism during pregnancy. The model includes all women and is adjusted for maternal BMI and age in trimester 1, and for gestational age at GDF15 measurement.

\begin{tabular}{|c|c|c|c|c|c|}
\hline & Glucose $\mathrm{T} 1$ to $\mathrm{T} 3$ & Glucose $\mathrm{T} 1$ to $\mathrm{T} 3$ & Insulin $\mathrm{T} 1$ to $\mathrm{T} 3$ & Insulin $\mathrm{T} 1$ to $\mathrm{T} 3$ & HOMA- \\
\hline & $\beta$ & $p$ & $\beta$ & $p$ & $\beta$ \\
\hline GDF15 T1 & 0.022 & 0.871 & -0.026 & 0.818 & -0.005 \\
\hline GDF15 T2 & -0.088 & 0.616 & 0.202 & 0.144 & 0.174 \\
\hline GDF15 T3 & -0.096 & 0.480 & 0.045 & 0.684 & -0.007 \\
\hline 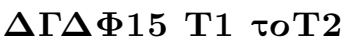 & -0.136 & 0.426 & 0.293 & 0.027 & 0.242 \\
\hline 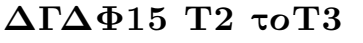 & -0.214 & 0.131 & 0.016 & 0.890 & -0.095 \\
\hline$\Delta \Gamma \Delta \Phi 15$ T1 & -0.103 & 0.449 & 0.065 & 0.593 & -0.007 \\
\hline
\end{tabular}

Significant associations in bold $(p<0.05)$. T1, trimester 1; T2, trimester 2; T3, trimester 3; HOMA-IR, homeostatic model assessment for insulin resistance; HOMA-B, homeostatic model assessment for beta cell function

\section{Figure legends}

Figure 1. A) GDF15 serum levels during and after pregnancy in women of normal weight or with obesity. Box included: GDF15 vales after pregnancy shown in greater detail. ${ }^{*} p<0.05$ for differences between NW and OB groups. $p<0.001$ for all increases between trimesters and for all differences between pregnancy and post-pregnancy values for both groups. Values are mean \pm SEM. B) Correlation between GDF15 levels and fat free mass at T3. C) Correlation between GDF15 levels and fat mass at 18 months after pregnancy. D) Maternal GDF serum levels in T1 depending on fetal gender. NW (closed circles), women of normal-weight; OB (open circles), women with obesity; T1, trimester 1; T2, trimester 2; T3, trimester 3; 6m, 6 months after delivery; 12m, 12 months after delivery; $18 \mathrm{~m}, 18$ months after delivery.

Figure 2. Associations between changes in fasting glucose and changes in GDF15 during pregnancy. (A) Changes in fasting glucose between T2 and T3 as a function of changes in GDF15 between T1 and T2. (B) Changes in fasting glucose between T2 and T3 as a function of changes in GDF15 between T2 and T3.The adjusted model includes maternal BMI and age at T1 as covariates. NW, women of normal-weight; OB, women with obesity; T1, trimester 1; T2, trimester 2; T3, trimester 3.

\section{Hosted file}

Andersson-Hall_Figure 1 BJOG.docx available at https://authorea.com/users/350962/articles/ 475649-growth-differentiation-factor-15-levels-in-obese-and-healthy-pregnancies-andits-relation-to-insulin-resistance-and-insulin-secretory-function-a-longitudinal-studyduring-and-after-pregnancy

\section{Hosted file}

Andersson-Hall_Figure 2 BJOG.docx available at https://authorea.com/users/350962/articles/ 475649-growth-differentiation-factor-15-levels-in-obese-and-healthy-pregnancies-andits-relation-to-insulin-resistance-and-insulin-secretory-function-a-longitudinal-studyduring-and-after-pregnancy 